\title{
EFEK TURBULATOR LOUVERED STRIP TWISTED TERHADAP KINERJA DOUBLE TUBE HEAT EXCHANGER
}

\author{
Oleh : \\ AHMAD ROBIUL AWAL UDIN, AZAMATAUFIQ BUDIPRASOJO *)
}

\begin{abstract}
ABSTRAK
Pengaruh turbulator terhadap kinerja aliran turbulen pada double tube heat exchanger dapat memecah (partitioning) dan mengganggu (blockage) pola streamline dari fluida yang mengalir ke saluran pipa dalam (inner tube) sehingga mengakumulasi aliran turbulensi dan meningkatkan laju perpindahan kalor dalam pipa. Penelitian Louvered strip twisted ini memiliki variasi sudut serang $\left(\theta=15^{\circ}, 25^{\circ}, 30^{\circ}\right)$ yang terpasang ditengah pipa bagian dalam dan searah aliran fluida masuk. Laju aliran fluida (air) panas di bagian pipa dalam diteliti dengan interval 400 lt/jam sampai 900 lt/jam dan laju aliran air dingin di bagian pipa luar konstan 900 lt/jam. Kinerja dari double tube heat exchanger meliputi laju perpindahan kalor $\left(Q_{\triangle L M T D}\right)$, faktor gesekan $(f)$, NTU (Number of Transfe Unit). Data hasil pengujian dari masing - masing sudut serang turbulator ini dibandingkan data tanpa turbulator (plain tube), secara keseluruhan terjadi peningkatan laju perpindahan kalor sebesar $40 \%$ sampai $72 \%$ dari pada tanpa turbulator serta menghasilkan faktor gesekan dari $51 \%$ sampai $61 \%$. Dengan performance ratio rata -rata tertinggi pada turbulator dengan sudut $30^{\circ}$ sebesar 0,995.
\end{abstract}

Kata kunci : Faktor gesekan, Heat Exchanger, Louvered Strip Insert, Turbulator Heat Exchanger.

\section{PENDAhUluan}

Peningkatan efisiensi dari perpindahan energi perlu adanya perubahan parameter - parameter, antara lain perubahan parameter aliran fluida (turbulensi), perubahan area penerimaan energi dan pengkondisian temperatur fluida kerja. Faktor perubahan parameter tersebut sangat penting dalam kontrol suatu proses Engineering baik di Power Plant Industry, Production Processing Utility dll, yang akan menentukan kualitas produk yang dihasilkan. Dalam dunia industri pemanfaatan kembali perpindahan energi atau panas sangat diperlukan, dimana perpindahan kalor dapat berlangsung melalui 3 cara, antara lain perpindahan kalor secara molekuler (konduksi), secara aliran (konveksi), secara gelombang elektromagnet (radiasi). Aplikasi perpindahan kalor tersebut banyak ditemui secara rinci dengan penggunaan Heat Exchanger baik berupa kondensor, recuperator, boiler dll. Heat exchanger adalah peralatan yang digunakan untuk memindahkan energi termal (Entalpi) antara dua atau lebih fluida, antara permukaan padat (solid) dan cair/gas, atau antara partikel padat dan partikel cair/gas, pada perbedaan temperatur dan area kontak termal fluida/konveksi paksa, sedangkan proses perpindahan kalor HE ada dua yaitu tipe direct dan indirect. Pengembangan perpindahan kalor dari HE terbagi menjadi beberapa teknik yaitu secara techniq passive dan active : Pengembangan HE passive techniq yaitu merekayasa aliran fluida kerja melalui penambahan area permukaan perpindahan panas (turbulator) pada pipa - pipa HE seperti pengasaran permukaan dinding dalam/luar pipa, alat pemusar aliran/swirler/penghalang, external atau internal fin, dll. Sedangkan secara active techniq yaitu dengan memberikan penambahan energi ke fluida kerja seperti pemberian getaran secara mekanik ke area fluida kerja agar dapat memecah lapisan batas kalor. Pengembangan perpindahan kalor dari Heat exchanger dimaksudkan untuk mengatasi permasalahan permasalahan seperti laju perpindahan kalor, area pemukaan perpindahan kalor, faktor gesekan, pola aliran fluida kerja, daya pompa, jenis Heat Exchanger yang digunakan, serta jenis material HE. Dalam penelitian ini akan mengembangkan teknik passive yaitu dengan memodifikasi dan menggabungkan tipe turbulator insert $H E$ Louvered strips Insert dan Twisted tape Insert atau disebut "Louvered Strip Twisted Inserts (LSTI)" yang memiliki variasi sudut serang sirip $\theta=15^{\circ}$, $25^{\circ}$ dan $30^{\circ}$. Pemasangan turbulator juga menerapkan konveksi paksa, hal ini berkaitan dengan besarnya energi diterima ke dalam fluida maupun perpindahan kalor antar pipa dan fluida.

\section{METODE PENELITIAN}

\subsection{PERALATAN PENELITIAN}

Dalam penelitian ini menggunakan double tube heat exchanger (gambar 1), dengan pipa bagian luar dari stainles steel berdiameter dalam 76,2 mm dengan dan pipa bagian dalam dari tembaga bediameter $25,4 \mathrm{~mm}$ dengan panjang 1,1 meter. Fluida yang digunakan adalah air baik pada pipa 
bagian luar (shell) dan pipa bagian dalam (tube) sedangkan arah aliran dalam heat exchanger ini yaitu counter flow. Untuk kerugian pipa dan kerugian panas ke lingkungan diabaikan karena sistem dianggap steady. Pengukuran pressure drop pada pipa bagian dalam menggunakan manometer. Air dingin mengalir konstan pada pipa luar (shell) 900 lt/jam dan temperaturnya dijaga konstan $27^{\circ} \mathrm{C}$. Sedangkan pada air panas mengalir pada pipa dalam (tube) bervariasi dari 400 lt/jam sampai 900 lt/jam dengan kenaikan interval 100 lt/jam dan temperatur reservoirnya konstan $65^{\circ} \mathrm{C}$ dengan toleransi temperatur $\pm 0,1^{\circ} \mathrm{C}$. Untuk menjaga temperatur air panas maka digunakan daya heater 2400 KW serta menggunakan automatic thermocontroler sedangkan untuk menjaga temperatur reservoir dingin maka digunakan sirkulasi dengan air PDAM. Louvered strip twisted insert (LSTI) ini terbuat dari stainless steel dengan variasi sudut serang $\theta=15^{\circ}, 25^{\circ}, 30^{\circ}$. Ukuran dan bentuk turbulator ini seperti pada gambar 2 .

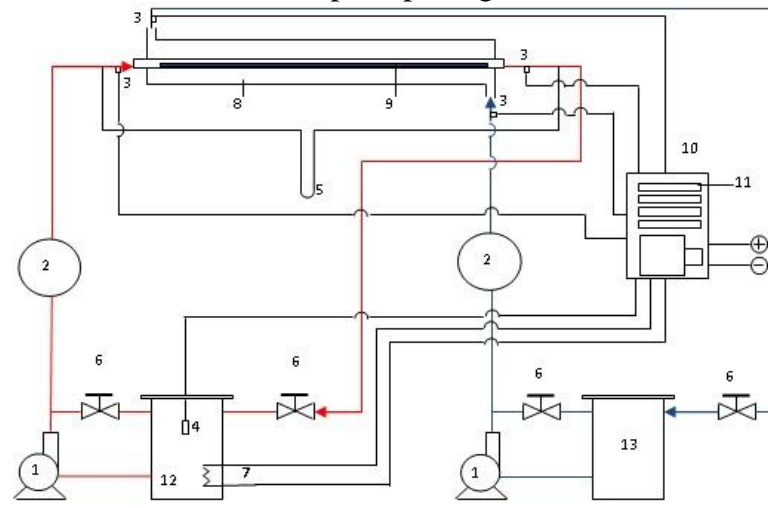

Gambar 1. Skema peralatan penelitian:1 pompa air 1/4 PK, 2 Debit meter, 3 LM 35, 4 Thermocouple tipe K, 5 Manometer, 6 Ball Valve, 7 Heater, 8 Double tube HE, 9 Louvered strip twisted insert, 10 control panel, 11 Display digital, 12 \& 13 Reservoir air panas dan dingin.

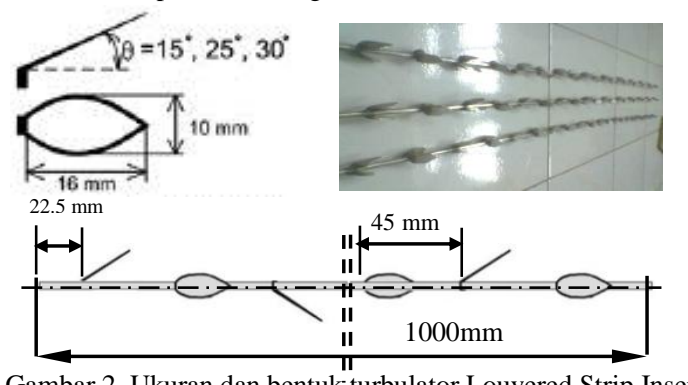

Gambar 2. Ukuran dan bentuk turbulator Louvered Strip Insert

\subsection{PROSEDUR PENELITIAN}

Dalam penelitian ini air dimasukkan ke reservoir air panas dan air dingin. Kemudian dilakukan kalibrasi pada debit meter untuk air dingin sebesar 900 lt/jam dan debit meter air panas dari 400 lt/jam - 900 lt/jam dimana kalibrasi ini dilakukan tiap kenaikan interval $100 \mathrm{lt} / \mathrm{jam}$. Air pada reservoir panas dipanaskan dengan heater sampai suhunya $65^{\circ} \mathrm{C}$, setelah itu pompa air panas dinyalakan untuk mengalirkan air kedalam pipa dalam (tube) sampai kondisi steady pada temperatur $\mathrm{T}_{\text {hin }}\left(65^{\circ} \mathrm{C}\right)$ dan $\mathrm{T}_{\text {hout }}$ yang terbaca pada display digital serta steady perbedaan ketinggiannya yang terukur pada manometer. Dan selanjutnya reservoir air dingin yang berkondisi steady pada suhu $27^{\circ} \mathrm{C}\left(\mathrm{T}_{\text {cin }}\right)$ dialirkan ke dalam pipa luar (shell) melalui pompa air dingin. Setelah itu dilakukan pencatatan dan pengambilan data 5 kali dengan pengulangan 3 kali dari temperatur $\mathrm{T}_{\text {hin }}, \mathrm{T}_{\text {hout }}, \mathrm{T}_{\text {cin }}, \mathrm{T}_{\text {cout }}$ dan $\Delta \mathrm{z}$ (perbedaan ketinggian $\mathrm{cmH}_{2} \mathrm{O}$ ). Prosedur penelitian ini dilakukan pada plain tube dan Heat exchnager dengan turbulator Louvered strip twisted insert.

\section{METODOLOGI}

Perubahan temperatur $\mathrm{T}_{\text {hin }}, \mathrm{T}_{\text {hout }}, \mathrm{T}_{\text {cin }}, \mathrm{T}_{\text {cout }}$ berpengaruh terhadap propertis fluida antara lain $\operatorname{Pr}, \rho, c p, v, k, \mu$ berdasarkan temperatur rata - rata fluida dingin dan fluida panas (temperatur bulk),
$T_{\text {bulk hot }}=\left(T_{\text {hin }}+T_{\text {hout }}\right) / 2$
$T_{\text {bulk cold }}=\left(T_{\text {cin }}+T_{\text {cout }}\right) / 2$

Karena aliran fluida pada double tube heat exchanger ini crossflow maka ;

$$
\Delta T_{L M T D}=\frac{\Delta T_{1}-\Delta T_{2}}{\ln \left(\Delta T_{1} / \Delta T_{2}\right)}
$$

dengan $\Delta T_{1}=T_{h, \text { in }}-T_{c, \text { out }}$ dan $\Delta T_{2}=T_{h, \text { out }}-T_{c, \text { in }}$ Luasan permukaan total perpindahan kalor $A_{s}$;

As = Luasan permukaan pipa dalam + Luas total

\section{turbulator}

Dimana luas total sirip ini dipengaruhi sudut sinus dari louvered strip twisted insert $\theta=15^{\circ}, 25^{\circ}$ dan $30^{\circ}$. Koefisien perpindahan kalor U ;

$$
U=\frac{1}{\frac{1}{h_{i} A_{i}}+\frac{\ln \left(D_{o} / D_{i}\right)}{2 \pi k L}+\frac{1}{h_{o} A_{o}}}
$$

Dimana $\mathrm{A}_{\mathrm{i}}$ dan $\mathrm{A}_{\mathrm{o}}$ adalah luasan total permukaan perpindahan kalor pipa dalam bagian dalam ; $A_{o}=\pi D_{o} L$ dan $A_{i}=\pi D_{i} L$

Maka laju perpindahan kalor double tube heat exchanger;

$$
Q=U A_{s} \Delta T_{L M T D}
$$

Sedangkan capacity ratio (c) dan Number of Transfer Unit :

$$
\begin{aligned}
N T U & =\frac{U A_{s}}{C_{\min }}=\frac{U A_{s}}{\left(\dot{m} C_{p}\right)_{\min }} \\
c & =\frac{C_{\min }}{C_{\max }}
\end{aligned}
$$

Hubungan antara NTU dan capacity ratio (c) terhadap efektivitas $(\varepsilon)$ pada counter flow heat exchanger, sebagai berikut :

$$
\varepsilon=\frac{1-\exp [-N T U(1-c)]}{1-c \exp [-N T U(1-c)]}
$$

Sedangkan faktor gesekan didalam pipa untuk aliran turbulen dipengaruhi besarnya penurunan tekanan $(\Delta P)$ sebagai akibat adanya hambatan dari pemasangan turbulator louvered strip twisted kedalam pipa heat exchanger; 
Ahmad Robiul AU dan Azamataufiq B, Efek Turbulator Louvered Strip Twisted Insert Terhadap Kinerja Double Tube Heat Exchanger

$$
f=\frac{\Delta P}{\left(\frac{L}{D}\right)\left(\rho \frac{u^{2}}{2}\right)}
$$

\section{HASIL DAN PEMBAHASAN EFEK LOUVERED STRIP TWISTED INSERT (LSTI)}

Dari hasil penelitian pemasangan Louvered strip twisted insert (LSTI) dengan variasi sudut serang $\theta$ $=15^{\circ}, 25^{\circ}, 30^{\circ} \mathrm{ke}$ dalam pipa bagian dalam double tube heat exchanger. Dari gambar 3.a terlihat peningkatan laju perpindahan kalor rata - rata (Qheat exchanger) $40 \%$ untuk LSTI 15, $62 \%$ untuk LSTI 25 dan $72 \%$ untuk LSTI 30 dibanding nilai laju perpindahan kalor rata-rata tanpa turbulator seiring kenaikan variasi debit aliran fluida panas. Kenaikan laju perpindahan kalor ini diakumulasi oleh kenaikan koefisien laju perpindahan kalor (U) yang ditunjukkan pada gambar 3.b, pengaruh penambahan luasan area perpindahan kalor $\left(A_{s}\right)$ juga besarnya perubahan temperatur akibat adanya pencampuran lapisan batas termal sehingga akan mempengaruhi propertis fluida tersebut $\left(\Delta \mathrm{T}_{\mathrm{LMTD}}\right)$ (pers 5). Hal ini dapat dijelaskan pengaruh bentuk sinus penampang (1 dimensi) dari luasan turbulator sehingga luasan aliran fluida berkurang atau terjadi hambatan dan selanjutnya pola streamline dari fluida yang mengalir ke saluran pipa dalam (inner tube) akan terpecah (partitioning) dan terganggu (blockage). Dengan kata lain akan mengalirkan aliran fluida sesuai dengan arah vektor pergerakkan fluida sesuai dengan bentuk dan model turbulator LSTI tersebut. Akibatnya lintasan dan luasan bebas alir fluida dalam pipa berkurang sehingga akan meningkatkan kecepatan alir fluida yang menimbulkan gerak partikel fluida semakin acak dan saling berinteraksi antar lapisan partikel dan dinding pipa untuk melepaskan kalor.

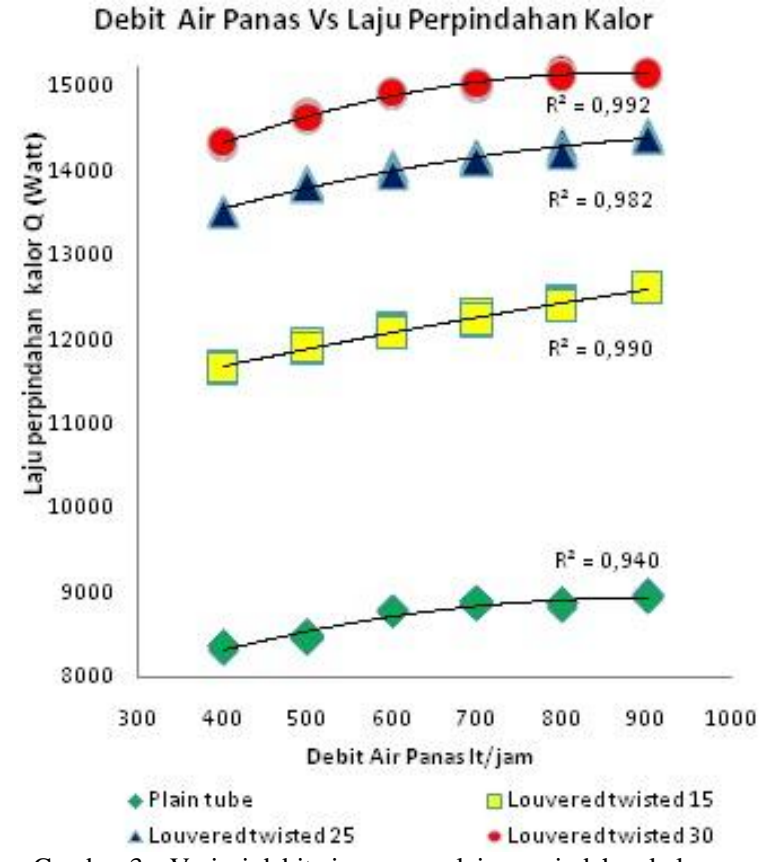

Gambar 3.a Variasi debit air panas vs laju perpindahan kalor

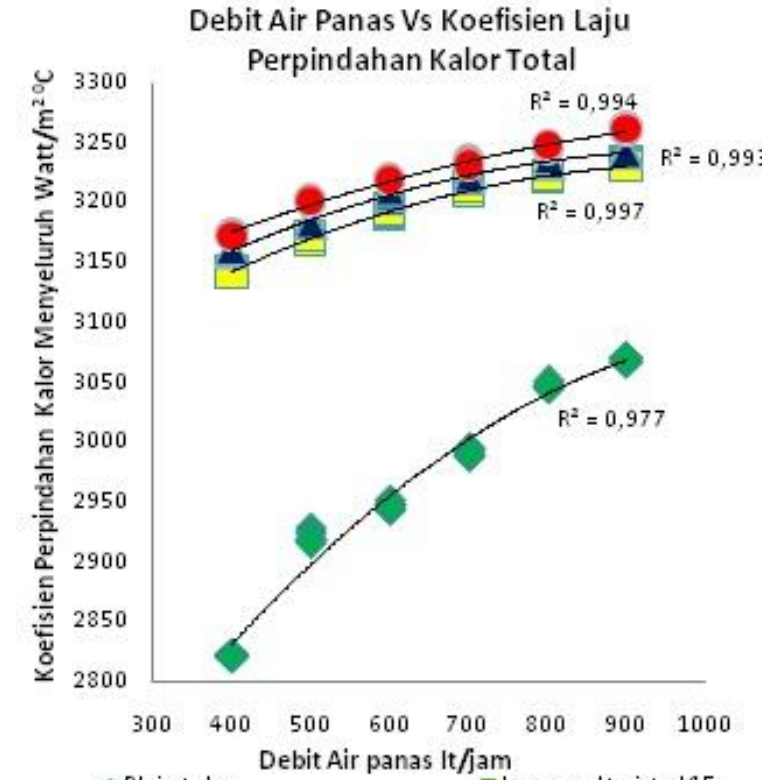

- Plain tube $\quad$ Louvered twisted 15

4. Louveredtwisted $25 \quad$ Louvered twisted 30

Gambar 3.b Variasi debit air panas vs koefisien laju perpindahan kalor

Dari gambar 3.a dan 3.b nilai laju perpindahan kalor dan koefisien laju perpindahan kalor maksimum dihasilkan oleh LSTI 30 dibanding LSTI 25 dan LSTI 15. 
Ahmad Robiul AU dan Azamataufiq B, Efek Turbulator Louvered Strip Twisted Insert Terhadap Kinerja Double Tube Heat Exchanger
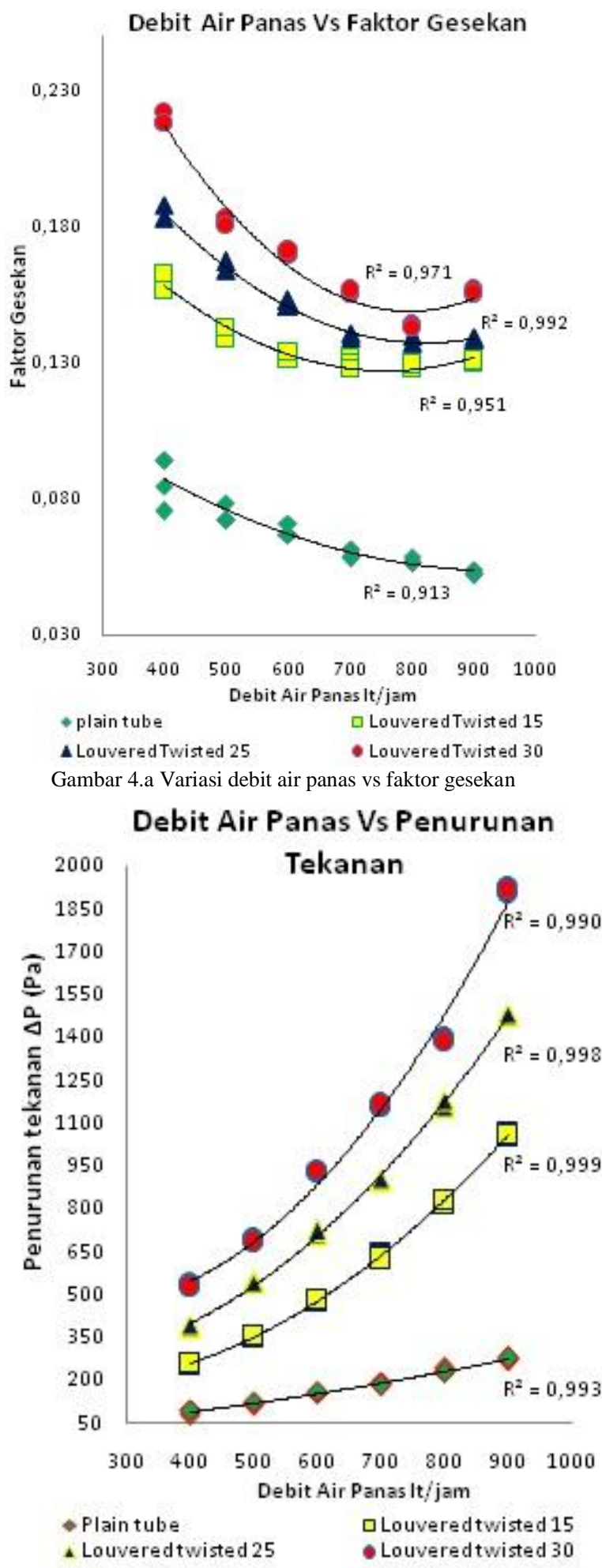

Gambar 4.b Variasi debit air panas vs penurunan tekanan

Gambar 4.a menunjukkan pengaruh pemasangan LSTI terhadap faktor gesekan dengan peningkatan variasi debit fluida. Secara umum terjadi penurunan faktor gesekan secara parabolik seiring peningkatan debit air panas. Faktor gesekan LSTI 30 mengalami peningkatan yang lebih besar dari LSTI 25 dan LSTI 10, namun secara keseluruhan faktor gesekan dari LSTI ini lebih besar dibanding tanpa turbulator begitu pula dengan penurunan tekanan yang diakibatkan pemasangan LSTI. Hal ini dapat dijelaskan dengan adanya turbulator LSTI maka hambatan alir fluida didalam pipa (akumulasi major dan minor losses) semakin besar artinya luasan alir fluida semakin berkurang sedangkan debit air panas konstan maka kecepatan tangensial fluida semakin besar artinya fluida tersebut dipaksa mengikuti alur atau model LSTI sehingga gesekan antar fluida dengan pipa dalam juga meningkat. Dan kecepatan tangensial ini merupakan pengaruh dari kemiringan sudut LSTI. Sesuai dengan (pers 8) jika kecepatan fluida meningkat maka faktor gesekannya terus menurun secara parabolik serta diikuti penurunan tekanan terus bertambah (gambar 4.b), hal ini disebabkan faktor kuadratik dari kecepatan tangensial fluida mengalami peningkatan lebih besar dibanding dengan penurunan faktor gesekan. Dari penilitian ini faktor gesekan mengalami peningkatan rata rata $51 \%$ untuk LSTI 10, $56 \%$ untuk LSTI 25 dan $61 \%$ untuk LSTI 30 dari nilai rata - rata faktor gesekan tanpa turbulator.

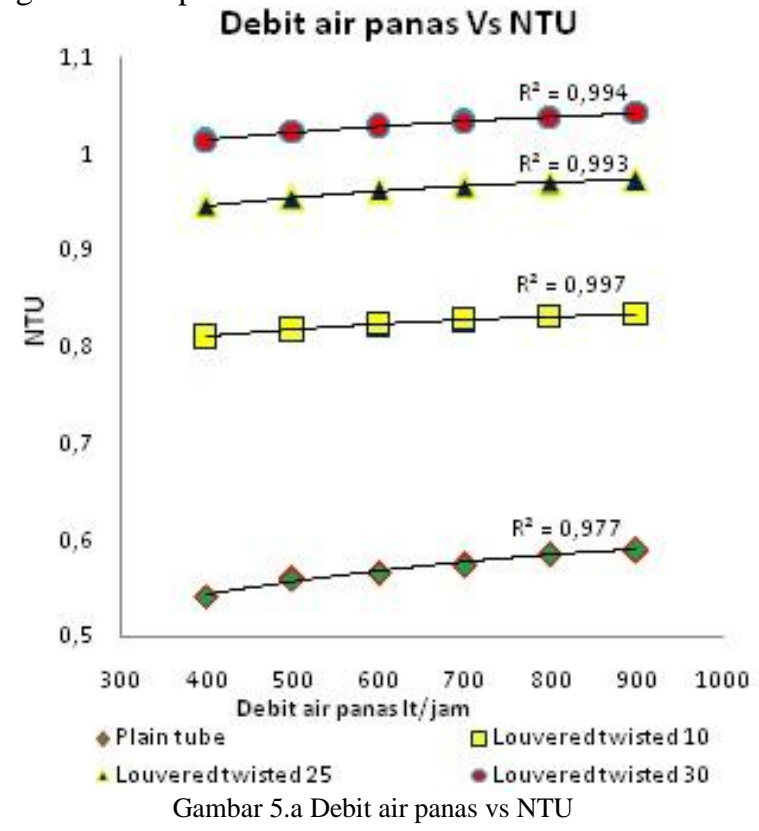


Ahmad Robiul AU dan Azamataufiq B, Efek Turbulator Louvered Strip Twisted Insert Terhadap Kinerja Double Tube Heat Exchanger

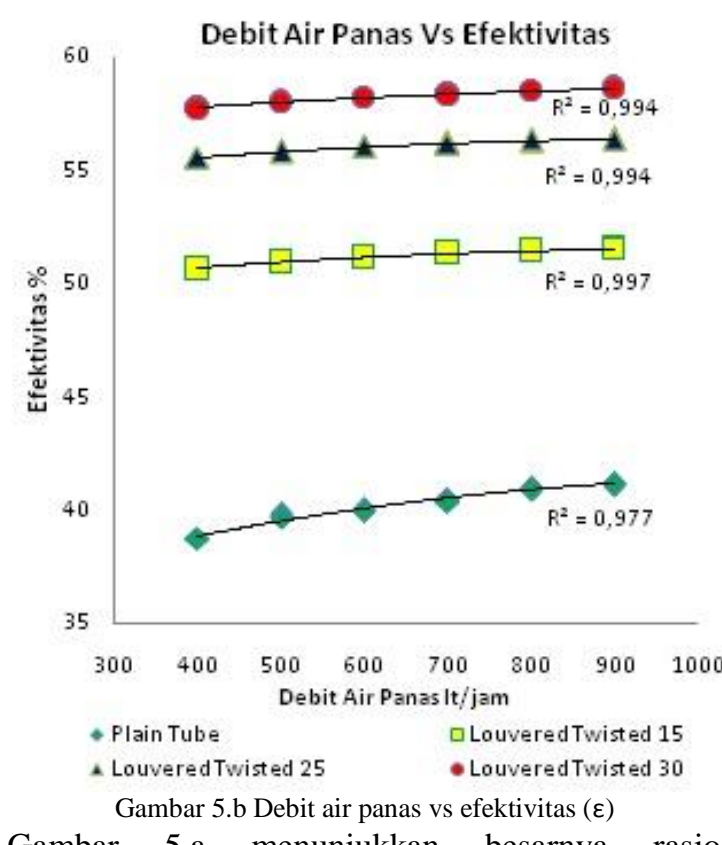

Gambar 5.a menunjukkan besarnya rasio perpindahan kalor menyeluruh yang dihasilkan oleh double tube heat exchanger (NTU). Secara keseluruhan dengan pemasangan LSTI ini meningkatkan nilai NTU heat exchanger dari pada tanpa turbulator, hal ini dipengaruhi peningkatan koefisien laju perpindahan kalor menyeluruh (U) dan bertambahnya luasan area perpindahan kalor $\left(A_{s}\right)$ akibat pengaruh bentuk dan sudut dari LSTI hal ini sesuai dengan rumus pers (9a). Begitu juga dengan gambar 5.b jika NTU meningkat sedangkan capacity ratio (pers 9b) konstan pada pengukuran tiap debit air panas maka efektivitas heat exchanger dari pemasangan LSTI akan meningkat dari pada tanpa turbulator (pers 10). Peningkatan rata - rata koefisien NTU paling signifikan sebesar $81 \%$ untuk LSTI 30, $69 \%$ untuk LSTI 25 dan 44,7 \% untuk LSTI 10 jika dibandingkan dengan nilai rata - rata NTU plain tube. Begitu juga peningkatan rata - rata efektivitas double tube heat exchanger maka LSTI 30 mengalami peningkatan sebesar $45 \%$, LSTI 25 peningkatannya $40 \%$ dan LSTI 10 peningkatannya $27,5 \%$ dari efektivitas rata - rata plain tube.

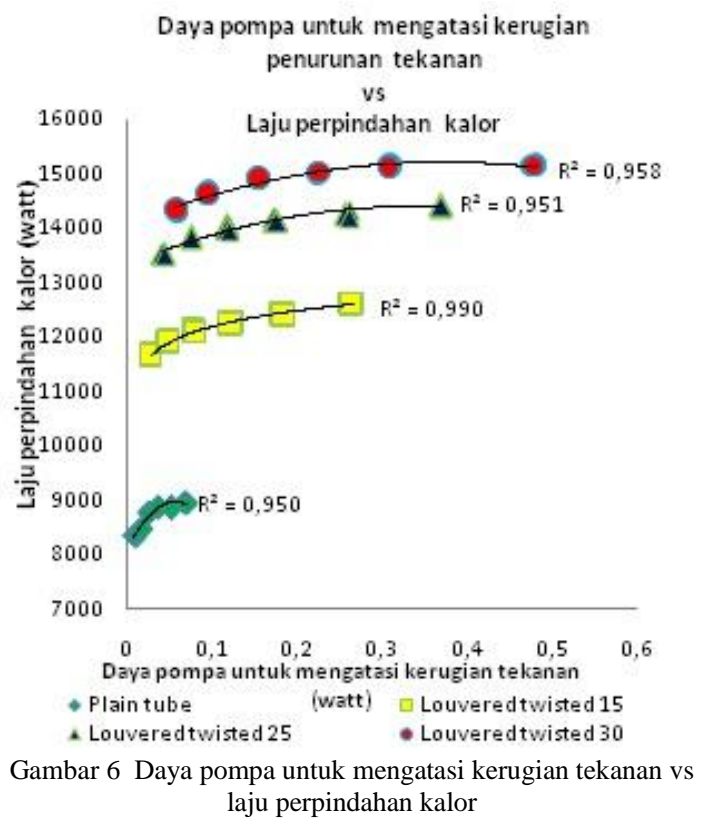

Dapat dilihat dari gambar 6 yang menyatakan hubungan antara daya pompa yang dibutuhkan untuk mengatasi kerugian penurunan tekanan, dimana untuk rata-rata daya pompa yang sama dengan plain tube maka laju perpindahan kalor rata - rata yang dihasilkan dengan pemasangan LSTI akan meningkat sebesar $62 \%$ untuk LSTI 30, $52 \%$ untuk LSTI 25, $34 \%$ untuk LSTI 10. Hal ini disebabkan adanya peningkatan hambatan dari LSTI ini yang menyebabkan kecepatan alir fluida semakin cepat sehingga penurunan tekanan juga akan terkoreksi.

\section{KESIMPULAN \& SARAN}

\subsection{Kesimpulan}

Penelitian variasi sudut serang Louvered Strip Twisted Insert $\theta=15^{\circ}, 25^{\circ}$ dan $30^{\circ}$ terhadap laju perpindahan kalor dan faktor gesekan terhadap aliran turbulen dalam meningkatkan kemampuan proses perpindahan kalor dari double tube heat exchanger menghasilkan :

1. Secara keseluruhan laju perpindahan kalor di semua variasi sudut serang LSTI mengalami peningkatan dibandingkan dengan plain tube (tanpa turbulator). Laju perpindahan kalor untuk LSTI 30 mengalami peningkatan rata rata sebesar $72 \%$ dari plain tube tepatnya pada $Q_{\text {heat exchanger }}=15158,04643$ watt dengan debit air panas $900 \mathrm{lt} / \mathrm{jam}$. Sedangkan koefisien NTU paling signifikan sebesar $81 \%$ untuk LSTI 30, $69 \%$ untuk LSTI 25 dan 44,7 \% untuk LSTI 10 jika dibandingkan dengan nilai rata - rata NTU plain tube. Begitu juga peningkatan rata - rata efektivitas double tube heat exchanger maka LSTI 30 mengalami peningkatan sebesar $45 \%$, LSTI 25 
peningkatannya $40 \quad \%$ dan LSTI 10 peningkatannya $27,5 \%$ dari efektivitas rata rata plain tube.

2. Sedangkan faktor gesekan pada LSTI 30 mengalami peningkatan rata - rata sebesar 61 $\%$ dari faktor gesekan rata - rata plain tube tepatnya pada $f=0,155$ dengan debit air panas 900 lt/jam.

4.2 Saran

1. Pengujian Heat Exchanger LSTI ini dapat dilanjutkan dengan perubahan interval debit aliran fluida tiap $50 \mathrm{lt} / \mathrm{jam}$ untuk mengkomparasikan data yang sudah ada sehingga dapat diketahui model grafik yang lebih akurat.

2. Dalam penelitian Heat Exchanger diperlukan kalibrasi ulang dan pengecekan sensor temperatur sehingga pengambilan data valid tidak terjadi penyimpangan yang signifikan

\section{UCAPAN TERIMA KASIH}

Kami ucapkan terima kasih atas selesainya penelitian dan penulisan jurnal ini kepada :

1. Ir. Nanang Dwi Wahyono, MM selaku Direktur Politeknik Negeri Jember.

2. Ir. Abi Bakri, M.Si selaku Wakil Direktur Bidang Akademik Politeknik Negeri Jember.

3. Ir. Michael Joko Wibowo, MT selaku Ketua Pusat Penelitian dan Pengabdian Mayarakat Politeknik Negeri Jember.

4. Ketua Jurusan Teknik.

5. Kepala Laboratorium Mesin Otomotif.

\section{DAFTAR PUSTAKA}

Bergles, A.E. 1998. The imperative to enhance heat transfer, in : Energy conservation through heat transfer enhancement of heat exchangers. NATO Advanced Study Institute. Izmir - Turkey.

Byron Black of the Brown Fintube Company. Heat transfer innovators. URL : http://www.kochheattransfer.com/cp/userfil e_Byron_black_of_the_brown_fintube_co mpany.pdf. 16 februari 2010.

Cengel, Yunus A. 2003. Heat Transfer A Practicaol Approach, $2^{\text {nd }}$ edition. New York:McGraw-Hill Companies Inc.

Durst, Franz. 2008. Fluid Mechanics "An intoduction to the theory of fluid flows. Berlin Heidelberg : German. Springer Verlag, Inc.

Eiamsa-ard, Smith. \& Promvonge, P. 2006. Heat transfer characteristics in a tube fitted with helical screw-tape with/without core-rod inserts. Bangkok: King Mongkuts Institute of Technology Ladkrabang.
Eiamsa-ard, Smith. Pethkool, Somsak. Thianpong, Chinaruk. \& Promvonge, P. 2007 Turbulent Flow Heat Transfer and Pressure Loss in a Double Pipe Heat Exchanger with Louvered Strip Inserts. Bangkok: King Mongkuts Institute of Technology Ladkrabang.

Engineering data book III 5-1. Wolverine Tube Heat Transfer Data book. Wolverine Tube, Inc.

http://www.wlv.com/products/databook/ch2 2.pdf. 16 februari 2010 .

Incropera,F.P., De Witt, D.P. 1992. Fundamental of Heat Transfer, $6^{\text {nd }}$ edition. New York: John Willey and Sons.

Introduction to engineering heat transfer. URL : http://www.ocw.mit.edu/../10_part1_3.pdf. 16 Februari 2010.

Lunsford, Kevin M. 1998. Increasing heat exchanger performance. Bryan : Texas US. Bryan Research \& Engineering, Inc.

Murugesan, P. 2009. Heat transfer and pressure drop characteristics of turbulent flow in a tube fitted with trapezoidal-cut twisted tape insert. Department of Mechanical Engineering, K. S. Rangasamy College of Technology. International Journal of Academic Research. URL : www.ijar.lit.az.

Paul Singh, R. 2006. Design of a tubular heat exchanger. URL http://web2.clarkson.edu/projects/subraman ian/ch302/notes/designshelltube.pdf.

Pethkool, Somsak. Eiamsa-ard, Smith. Ridluan, Artit. And Promvonge, P. 2006 Effect of Louvered Strips on Heat Transfer in a Concentric Pipe Heat Excahanger. Bangkok:King Mongkuts Institute of Technology Ladkrabang.

Saunders, E.A.D. 1986. Heat Exchangers Selection, Design and Construction. Darlington : Whessoe Heavy Engineering Ltd.

Shah, Ramesh K. \& Sekulic, Dušan P. 2003. Fundamentals of Heat Exchanger Design. Hoboken, New Jersey : John Wiley \& Sons, Inc. 